\title{
Establishing a Six Sigma Green Belt Certification for Undergraduate Engi- neering Technology Students
}

\section{Dr. Wes Stone, Western Carolina University}

Dr. Wes Stone is an associate professor in the Department of Engineering and Technology at Western Carolina University in Cullowhee, NC. He earned his bachelors degree from the University of Texas at Austin, masters degree from Penn State, and PhD from Georgia Tech, all in Mechanical Engineering. His research interests include manufacturing processes and quality techniques. He also serves as the program director for Engineering Technology at WCU.

\section{Dr. Michael Sean June, Western Carolina University}

Dr. M. Sean June is an assistant professor in the Department of Engineering and Technology at Western Carolina University in Cullowhee, NC. He earned bachelor's degrees from both the State University College at Fredonia NY (Biology), and the Rochester Institute of Technology (Mechanical Engineering), a master's degree from the Rochester Institute of Technology (M.E.), and a PhD from North Carolina State University (M.E.). His research interests include electro-hydrodynamic flow, enhancement of heat transfer and propulsion. 


\title{
Establishing a Six Sigma Green Belt Certification for Undergraduate Engineering Technology Students
}

\begin{abstract}
The introduction of Six Sigma quality principles in industry has revolutionized production, as well as many other sectors of society. Academia has not moved as quickly to adjust its curricula, as it should to keep pace with the demands of industry. This paper documents the need and structure of a Six Sigma Green Belt Certification program, driven by the industrial advisory committee of the Engineering Technology program at Western Carolina University, a regional comprehensive university that works closely with its industrial partners in multiple modes. This new program is targeted at undergraduate Engineering Technology students, and takes advantage of two existing courses and capstone projects that coordinate nicely with this certification.
\end{abstract}

Keywords: Green Belt, Lean, Six Sigma, Quality, Certification

\section{Introduction}

The Engineering Technology (ET) program at Western Carolina University has built strong ties with regional industry over the past several decades, producing graduates who are ready to make an immediate impact on the job. Employers often compliment the ability of these graduates to contribute immediately, especially in a manufacturing setting.

The manufacturing base in the western North Carolina region is a strong mix of industries, such as automotive components, advanced aircraft engine composites, large truck axles, furniture, textiles, fiber optic cables, mountain bikes, camping equipment, and many more. The university serves as a regional comprehensive university, making the link with industry very natural. For several years, the ET program has enjoyed a strong relationship with regional industry in the form of industry-sponsored capstone projects with many of those focusing on new product development. ${ }^{1}$ In recent years there have been an increasing number of these capstone projects with an emphasis on quality and process improvement, which are at the heart of Lean Six Sigma.

With ABET (ETAC Commission) accreditation, the ET program meets regularly with its industrial advisory committee. Seven years ago that committee brought a recommendation to the faculty of the ET program: add a Lean Six Sigma course to follow the Quality Systems course already in the curriculum. That course has been added to the curriculum and is currently in its fifth year. Two years ago the advisory committee brought forth another recommendation: provide the ET students with a Green Belt Certification. Despite the prevalence of Lean Six Sigma in industry, these topics have not been adopted in engineering programs, as they should. Goldberg and Somerville refer to this as one of three "missed revolutions," the quality revolution (the other two are the entrepreneurial revolution and the information technology revolution). ${ }^{2}$

In a separate effort, the Department of Engineering and Technology secured a significant grant from the Golden Leaf Foundation, which is funding the development of advanced manufacturing to retrain the state's workforce, many of whom were displaced by the reform of the tobacco industry. This grant has supported the creation of articulation agreements between regional 
community colleges and the programs in the department, as well as the pursuit of ABET accreditation for the associates programs in engineering technology fields. Also included in this Golden Leaf grant is funding for the development of a Six Sigma Green Belt certification program within the Engineering Technology program, aligning well with the advisory committee's recommendation.

\section{Green Belt Certifications}

The target market for this Green Belt Certification at Western Carolina University is the undergraduate student population. Students in the ET program are now required to take two quality focused courses-Quality Systems (ET 331) and Lean Six Sigma (ET 334), taken typically in the junior year's fall and spring semesters, respectively. Additionally, these ET students, along with all students in similar programs in the department, are required to take a two-semester capstone project during the senior year. There are a variety of different Green Belt courses at universities throughout the country, spanning various audiences.

Rose-Hulman Institute of Technology has introduced a "Rose Belt" program, providing students with a 10-week curriculum focused intently on Lean Six-Sigma topics. ${ }^{3}$ The goal of this program is to give students exposure to these tools, so that when they see them in industry or when pursuing additional certification, they are well-practiced and have a higher probability of success.

East Carolina University has developed a modular Six Sigma Green Belt program that can be delivered in an online platform, such as Moodle ${ }^{\circledR}$ or Blackboard ${ }^{\circledR} .4$ They successfully employed the DMAIC (Define, Measure, Analyze, Improve, Control) methodology used in Six Sigma to create this program.

RIT (Rochester Institute of Technology) and Villanova University have created Green Belt certification programs that appeal to broader populations, such as working professionals, as well as students. Their pricing structure tends to focus their audience more on the former. At RIT the program is delivered in one-day segments for 12 consecutive weeks. The Villanova program is delivered as an eight-week course, thoroughly covering Lean Six Sigma topics. ${ }^{5,6}$

\section{A New Green Belt Program}

Using some of the lessons learned from similar university programs, coupled with the recommendations of the ET advisory committee, a new Green Belt Certification program was developed. A body of knowledge was first developed to cover the most common tools employed in Lean Six Sigma, as shown below:

Body of Knowledge for the Green Belt Certification:

General Lean and Six Sigma Information:

- History and origins of lean manufacturing and Six Sigma quality

- The DMAIC (Define, Measure, Analyze, Improve, Control) approach 
Lean-focused topics:

- Value stream mapping

- $5 \mathrm{~S}$

- Kaizen events

- Kanbans

- Line balancing

- Bottleneck management

- Poka yoke

- Setup reduction/SMED (single-minute exchange of dies)

- QFD (quality function deployment) and HOQ (house of quality)

Six Sigma-focused topics:

- Basic statistical tools

- The normal distribution and standard normal distribution

- DPMO (defects per million opportunities)

- The 1.5-sigma shift

- Cause-effect analysis

- Root cause analysis

- Measurement system analysis, Gage R\&R (repeatability \& reproducibility)

- T-Tests (1- and 2-sample)

- SPC (statistical process control), control charts

- Process capability analysis $\left(\mathrm{C}_{\mathrm{p}}, \mathrm{C}_{\mathrm{pk}}\right)$

- FMEA (failure modes \& effects analysis

- DOE (design of experiments)

- Regression analysis

Curricula for the two quality courses, ET 331 and ET 334, were adjusted to ensure that these topics were covered sufficiently to expose students to these crucial subjects. The revised curricula are in their second academic year of implementation, thus putting last year's students in their senior year, implementing their capstone projects during this academic year.

The four primary criteria for successful completion of the Green Belt Certificate are:

(1) Completion of the Quality Systems course (ET 331) with a grade of B or better.

(2) Completion of the Lean Six Sigma course (ET 334) with a grade of B or better.

(3) Completion of a separate gateway exam covering the entire body of knowledge with a grade of $80 \%$ or better.

(4) Completion of a Lean Six Sigma project to the satisfaction of the project sponsor.

Success in the two courses highlights the importance of this course to those students wishing to pursue a career in the field of Lean and/or Six Sigma. The gateway exam is one that is administered during the spring semester of their senior year, the same semester that they are completing their capstone projects. It is not likely that the juniors still taking ET 334 will be prepared to take the gateway exam, thus the focus on the senior year. 
The Lean Six Sigma project is one that is the hallmark of most Green Belt and Black Belt programs in academia, as well as industry. Those process/quality capstone projects mentioned previously fit perfectly into this criterion. Additional options for this project include other avenues, such as projects completed as a part of an independent study project, an internship, or a permanent job in industry. The successful project completion requires the approval of the project sponsor (typically the industry representative) with the concurrence of the Engineering Technology faculty.

\section{Conclusions}

This new Green Belt Certification grew naturally out of regional industry needs, communicated via the industrial advisory committee. Student interest has been strong, as they have seen the need for Lean Six Sigma tools through various exposure points-guest speakers, internships, job interviews, etc. Feedback from this inaugural class of Green Belt students will be channeled through the faculty, and then the industrial advisory committee.

As this program matures, it is envisioned that the same topics will be rolled out to working professionals, providing industry partners with an avenue for training, as well as aiding individuals in the region wishing to upgrade their marketability as they search for employment opportunities. The same Golden Leaf grant that enabled the development of this student-based Green Belt Certification will be used to launch a program for the regional non-student population.

\section{Acknowledgements}

These efforts were made possible through a Golden Leaf Grant (\#FY2014-046), entitled Fostering Tomorrow's Advanced Manufacturing Engineers: A University, Community Colleges, and Industry Collaborative Initiative. The authors would like to thank the Golden Leaf Foundation for this generous grant, as well as the Department of Engineering and Technology for providing the commitment to this worthwhile, industry-necessary endeavor.

\section{Bibliography}

[1] Stone, W. L., \& Chang, G. A. (2013). An Evolving Capstone Course used in ABET Assessment. Proceedings of the 2013 American Society for Engineering Education Annual Conference \& Exposition, Atlanta, GA, June 23-26, 2013.

[2] Goldberg, D. E., \& Somerville, M. (2014). A Whole New Engineer. Douglas, MI: ThreeJoy Associates, Inc.

[3] Downing, C. G. (2011). Using Design for Six Sigma Practices to Develop a "Rose" Belt Course. Proceedings of the 2011 American Society for Engineering Education Annual Conference \& Exposition, Vancouver, BC, June 26-29, 2011. 
[4] Jackson, A., Jackson, S., \& Mehta, Merwan. (2009). Applying The Six Sigma Process When Creating A Modular Six Sigma Green Belt Program. Proceedings of the 2009 American Society for Engineering Education Annual Conference \& Exposition, Austin, Texas, June 14-17, 2009.

[5] John D. Hromi Center for Quality \& Applied Statistics, Rochester Institute of Technology (2015). Green Belt Program [Website]. Retrieved from https://www.rit.edu/kgcoe/cqas/lean-six-sigma/green-belt-program

[6] Villanova University (2015). Six Sigma Green Belt [Website]. Retrieved from http://www.villanovau.com/programs/certificates/six-sigma/six-sigma-certificatecourses/six-sigma-green-belt/ 